\title{
The Survival of Escherichia coli on Drying and Rehydration
}

\author{
By B. R. RECORD, R. TAYLOR AND D. S. MILLER \\ Microbiological Research Establishment, Porton, Wiltshire
}

(Received 20 October 1961)

\begin{abstract}
SUMMARY
By direct observation of individual organisms in a micro-culture chamber and by viable plate counts, a study has been made of the function of sugar/colloid mixtures in promoting the survival of Gram-negative bacteria on drying. The high death rate after drying in sugar alone was due mainly to cell-wall damage caused during rehydration by the temporary osmotic pressure set up by the sugar within the cell, leading to the formation of spheroplasts not capable of division. Spheroplast formation was largely prevented and survival greatly enhanced by controlled rehydration, showing that the sugar component was the primary protective agent. The complementary role of the protein or 'protective colloid' appears to lie in its ability to compress the cell wall against the contracted plasma membrane in plasmolysed cells, thus decreasing the volume of the interspace between the two membranes and so limiting the sugar trapped therein to a safe amount. These observations were corroborated by cell volume measurements in the ultracentrifuge.
\end{abstract}

\section{INTRODUCTION}

Although the prime importance of the suspending medium in promoting a high survival of bacteria on drying has long been recognized (see review by Fry, 1954), the mode of action of an effective medium has not been satisfactorily explained. Broth and serum had been used with moderate success in most of the earlier work, but it was not until Fry \& Greaves (1951) introduced their mist. desiccans, a serum + broth mixture containing $\mathbf{7 . 5} \%$ glucose, that sugar-containing media came into general use for the preservation of bacteria in the dried state. Fry \& Greaves suggested that the function of the sugar lay in its ability to trap the small amount of moisture which they believed necessary for survival, although Record \& Taylor (1953) concluded (in view of the high survival maintained after prolonged rigorous drying) that the amount of moisture, if any, must be small indeed. Scott (1959) cast doubt on the moisture theory and proposed a chemical hypothesis based on carbonyl-amino group interactions. Neither hypothesis however explains the rather poor survival obtained in sugar alone nor the enhanced survival, first noted by Heller (1941) which results from the addition of colloidal material. The present paper reports certain physicochemical phenomena concerning both these factors.

\section{METHODS}

Organism. The Gram-negative organism Escherichia coli strain Jepp was chosen for most of the present work as an average representative of the coli group, being neither as robust as the 'Communis' strain nor as fragile as the American type ' $B$ ' 
(see Record \& Taylor, 1953). It was grown at $37^{\circ}$ in tryptic meat broth adjusted to $\mathrm{pH} 7 \cdot 4$.

Viable counts (Miles \& Misra, 1938) were made on tryptic meat agar (35 ml.) in Petri dishes $(8.7 \mathrm{~cm}$.). The nutrient agar was dried, after setting, for $1 \mathrm{hr}$. in an inverted position at $60^{\circ}$ to render it absorbent; $0.5 \mathrm{ml}$. of suspension containing 100-200 viable organisms was spread on the agar surface by rotation in an inclined position. The plates were incubated at $37^{\circ}$ overnight. Survivals are expressed as a percentage of the initial viable count.

Drying procedure. Samples of cultures grown in tryptic meat broth as above were diluted with buffer to about $10^{8}$ organisms $/ \mathrm{ml}$. and then further diluted to about $10^{6}$ organisms $/ \mathrm{ml}$. in the drying medium. Single drops (about $0.02 \mathrm{ml}$.) of this suspension were delivered to the bottom of small glass ampoules which were then attached by rubber connexions to a manifold system containing $\mathrm{P}_{2} \mathrm{O}_{5}$, evacuated to $\mathbf{0 . 1} \mathrm{mm}$. $\mathrm{Hg}$ or less (unless otherwise stated) and dried for 18-24 hr. The drops were weighed or delivered from a calibrated dropping pipette (Snyder, 1947). The dried drops were reconstituted with $5 \mathrm{ml}$. tryptic meat broth and diluted further with broth as required for viable counts.

Materials. Buffer contained (g./l.): $\mathrm{KH}_{2} \mathrm{PO}_{4} 4.5 ;\left(\mathrm{NH}_{4}\right)_{2} \mathrm{SO}_{4}, 0.5 ; \mathrm{NH}_{4} \mathrm{Cl} \mathrm{0.5}$; adjusted to $\mathrm{pH} 7 \cdot 6$ by addition of $\mathrm{NaOH}$. Peptone water was a solution of Evans 'bacteriological' peptone at $10 \mathrm{~g}$./l. D-Glucose was British Drug Houses Ltd. analytical grade. Bovine serum albumin (dried fraction V) was obtained from Armour Laboratories. Polyethylene glycol (PEG), average molecular weight 10,000, obtained from L. Light and Co., was dialysed in cellophane bags against distilled water for 3 days and freeze dried from a $100 \mathrm{~g}$./1. solution.

All reagents were adjusted to $\mathrm{pH} \mathbf{7 \cdot 3} \pm \mathbf{0 \cdot 3}$.

Microscopy. The study of the behaviour of individual organisms when subjected to various treatments was greatly facilitated by the use of a micro-culture chamber (Powell, 1956). The apparatus was set up in a temperature-controlled room at $30^{\circ}$. Observations were made by the use of a phase contrast optical system. For studies on freely growing organisms, peptone water was circulated beneath the cellophan membrane until two or three generations had appeared, after which the peptone water was replaced by the test solution. When the test solution contained a high molecular weight component which would not diffuse readily through the membrane, a centrifuged deposit of freely-growing organisms was taken in the test solution, the same solution being circulated through the chamber.

Pellet volume measurements. The analytical ultracentrifuge offers a convenient means of measuring pellet volumes at any desired centrifugal force over a wide range. A Spinco 'Model $E$ ' was used. Photographs were taken with the diagonal Schlieren bar angle set at $90^{\circ}$ to give, in the absence of any steep concentration gradient above the surface of the pellet, the position of the pellet boundary. A control run with water in the optical cell fixed the position of the cell bottom. Frequent observations were also made with a bar angle setting of $45^{\circ}$, to reveal the presence of any appreciable concentration gradients such as might result, for example, from the disintegration of some of the bacteria. On account of their fragility, bacteria in the logarithmic phase were generally unsatisfactory and pellet volume measurements were confined to bacteria obtained from cultures in tryptic meat broth incubated for $18 \mathrm{hr}$. at $37^{\circ}$. The culture was centrifuged, 
the deposit either washed with a large volume of water and taken up in water or washed and resuspended in $0 \cdot 15 \mathrm{M}-\mathrm{NaCl}$. The composition of the suspending medium was then adjusted by the addition of the required amount of $\mathrm{NaCl}$ or other material in the solid (usually the finely divided freeze-dried) state with gentle stirring. The resulting dilution of the bacterial suspension was calculated from the partial specific volume of the added substance. The suspensions used contained the equivalent of 25-50 $\mathbf{~ m g}$. dry wt. bacteria/ml. (determined by heating a known volume of the suspension in an air oven at $100^{\circ}$ ) giving, in the case of aqueous suspensions at high speed, a pellet layer $1 \cdot 0-\mathbf{2} \cdot 0 \mathrm{~mm}$. thick. The avoidance of excessive concentration gradients restricts the choice of colloid component and a polyethylene glycol of average molecular weight 10,000 was selected for these studies.

Osmotic and diffusion pressure measurements. Bags, sealed at one end and provided with a simple capillary manometer filled with mercury were made from Viscose dialysis tubing $(18 \mathrm{~mm}$. diam.), filled with the solution under test $(20 \mathrm{ml}$.) supported with an outer perforated metal tube and placed in a $500 \mathrm{ml}$. cylinder of water at $20^{\circ}$.

\section{RESULTS}

\section{The effect of some factors on survival on drying and rehydration}

The growth phase. The enhanced sensitivity of organisms in the logarithmic phase of growth to a variety of physical and chemical agents has been noted by numerous workers (e.g. Hegarty \& Weeks, 1940; Fry \& Greaves 1951; Annear, 1956). As seen in Fig. 1, Escherichia coli (Jepp) when subjected to drying and rehydration exhibited a similar behaviour, i.e. a decrease in survival as the organisms entered the logarithmic phase and a rapid increase on entry into the stationary phase. Tryptic meat broth was inoculated with an $18-\mathrm{hr}$. culture of the organism to give an initial concentration of about $10^{5} \mathrm{orgs} . / \mathrm{ml}$. and incubated at $37^{\circ}$. During the experiment samples were withdrawn and diluted with the glucose peptone medium before drying in order to maintain the concentration at about $10^{6} \mathrm{orgs} . / \mathrm{ml}$. The results emphasize the importance, in studies on survival, of stating the phase of growth of the organisms and avoiding, during an experiment, any transition from one phase to another. All the drying experiments described in this paper were carried out on organisms in the stationary phase by the use of $18 \mathrm{hr} .37^{\circ}$ cultures.

The temperature and conditions of drying. Although the glucose-containing media commonly used for preservation usually exhibit the normal appearance of a frozen mass during the initial evaporative freeze stage, they frequently show signs of bubbling and shrinkage during drying, leading finally to a glassy and scaly residue; it seems doubtful whether true freeze-drying from the solid phase is realized from such media. The survivals in these circumstances were compared with those obtained by drying in conditions when freezing could not take place, namely, by introducing a controlled leak into the vacuum system to maintain the pressure at $5 \mathrm{~mm}$ $\mathrm{Hg}$. during the first hour (the primary drying) thereafter decreasing the pressure to $\mathbf{0} \cdot \mathbf{1 ~ m m}$. Hg. for the remainder of the $24 \mathrm{hr}$. drying period. The results (Fig. 2) show that for Escherichia coli in the stationary phase, survival on drying in the glucose peptone medium was actually enhanced by avoiding the sharp decrease in temperature which accompanies evaporative freezing in high vacuum. Annear (1958) reached similar conclusions with organisms of the Salmonella group. 
Measured samples of the same suspensions in glucose peptone were also dropped on to the freeze-dried peptone starch plugs described by Annear (1956), thereby exposing the organisms to very high concentrations of peptone from the onset of drying. The survivals (Fig. 2) thus obtained showed no improvement over ordinary vacuum drying procedure.

The composition of the suspending fluid. Table 1 illustrates the complementary effect of sugar and protein in promoting survival on drying. The total concentration of glucose and bovine serum albumin was maintained constant at $200 \mathrm{~g}$. $/ \mathrm{l}$. In either sugar or protein alone survival was low, but good survival was obtained over a fairly wide range of mixtures of the two components. There appeared, however,

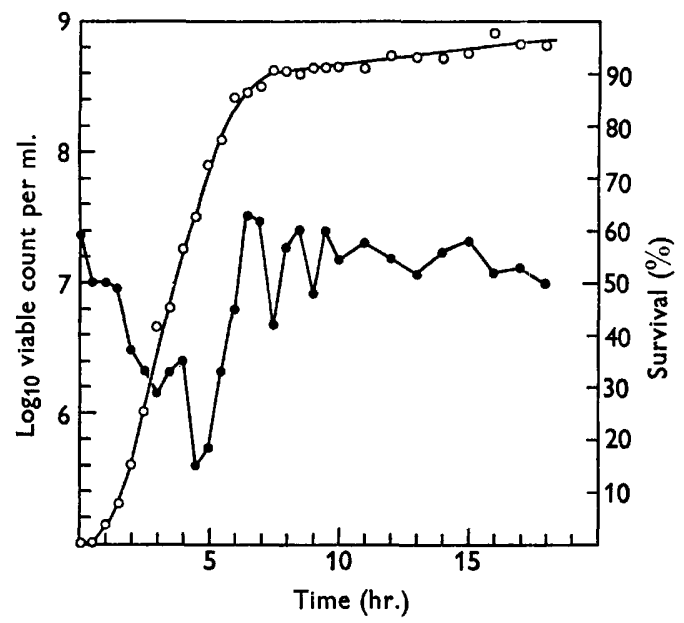

Fig. 1

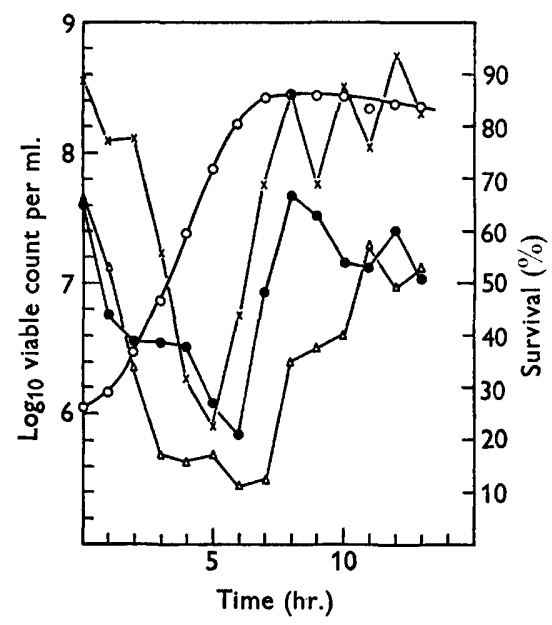

Fig. 2

Fig. 1. Growth of Escherichia coli and survival on drying. $\bigcirc$, Static growth in tryptic meat broth at $37^{\circ}$. 9 , \% survival after vacuum drying in $10 \%$ glucose $+10 \%$ peptone. Fig. 2. Growth of Escherichia coli and survival on drying. $O$, static growth curve in tryptic meat broth at $37^{\circ}$. $\%$, survival after vacuum drying in $10 \%$ glucose $+10 \%$ peptone. $\Delta, \%$ survival after vacuum drying on peptone + stareh plugs. $x, \%$ survival after primary drying at $+1^{\circ}(5 \mathrm{~mm}$. $\mathrm{Hg}$ pressure $)$.

Table 1. Survival of Escherichia coli (grown for $18 \mathrm{hr}$. at $37^{\circ}$, in tryptic meat broth) after drying in glucose + bovine serum albumin mixtures

$\begin{array}{lrrrrrrr}\text { Glucose (\%) } & 20 & 18 & 15 & 10 & 5 & 2 & 0 \\ \begin{array}{c}\text { Bovine serum } \\ \text { albumin (\%) }\end{array} & 0 & 2 & 5 & 10 & 15 & 18 & 20 \\ \begin{array}{c}\text { Survival (\%) } \\ \text { urval }\end{array} & 1.5 & 26 & 33 & 35 & 14 & 4 & 0 \cdot 1\end{array}$

to be no unique requirements for either sugar or protein for good survival. For example, similar results were obtained when the protein was replaced by transfusion dextran with a molecular weight $\mathbf{1 3 5 , 0 0 0}$. Good survival was still obtained when the glucose was replaced by various polyhydric alcohols and some preparations of tryptic meat broth offered excellent protection without any other additive, suggesting that the function of an effective preservative may be physical rather than chemical in character. 
The concentration of the components of the suspending fluid. The results of a more detailed study of the effect of varying the concentration of each component in a two component system is shown graphically in Fig. 3 for glucose and polyethylene glycol (PEG). The survival in either glucose or PEG alone was poor at any concentration; optimum survival was obtained in mixtures containing 5-10\% glucose and 2-10\% PEG. Although a $5 \%$ glucose $+5 \%$ PEG mixture gave a good survival, the same mixture diluted fivefold gave only about one-fifth the survival.

The rehydration procedure. Although drying in $10 \%$ glucose followed by direct rehydration with water or buffer gave only a few $\%$ survival this could be improved

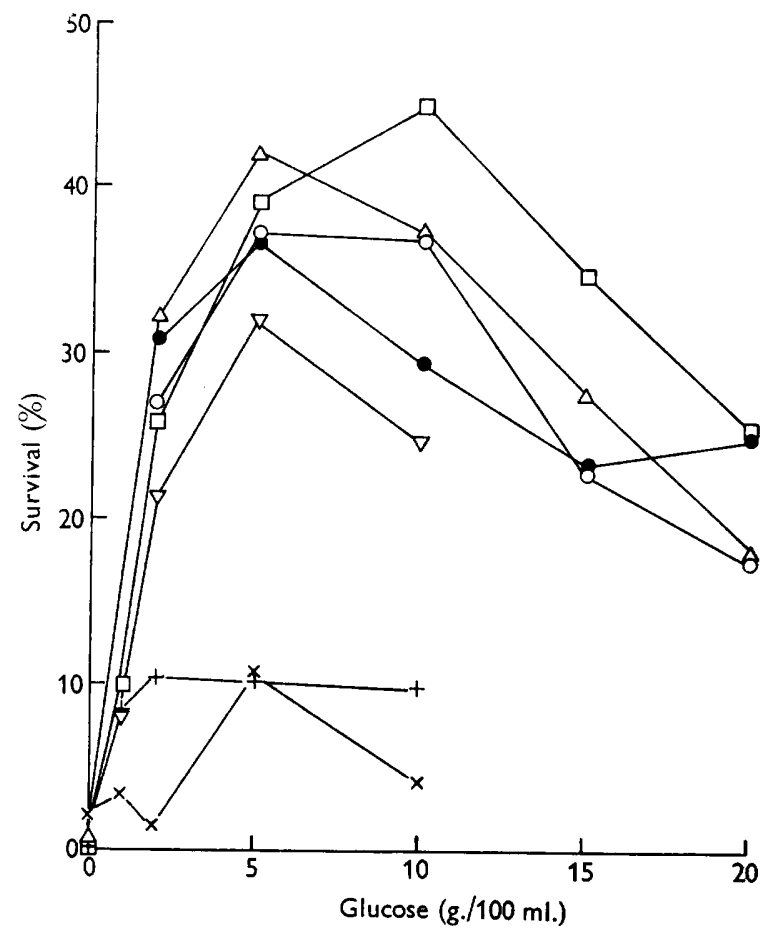

Fig. 3. Survival of Escherichia coli (stationary phase) on drying in glucose + polyethylene glycol mixtures. Polyethylene glycol concentration $(w / v): x, 0 \% ;+, 1 \% ; \nabla, 2 \%$; $\square, 5 \% ; \triangle, 10 \% ; 0,15 \% ; O, 20 \%$.

upon considerably by careful control. By reconstituting the dried sample in $\mathbf{5 0} \mathrm{g}$. glucose $/ 100 \mathrm{ml}$. solution, transferring to a cellophan dialysis bag immersed in $50 \mathrm{~g}$. glucose $/ 100 \mathrm{ml}$. solution at $2^{\circ}$ and slowly diluting the outer solution with buffer, with continuous stirring, during $6 \mathrm{hr}$. a recovery of $44 \%$ viable organisms was obtained.

\section{Observations on individual bacteria}

Information about the nature of the damage caused by rapid rehydration of Escherichia coli dried from $10 \%$ glucose was revealed by observations on individual bacteria in the micro-culture chamber.

Plasmolysis. Escherichia coli when placed in hypertonic solutions of various electrolytes or sugars exhibited the characteristic appearance of plasmolysis result- 
ing from the contraction of the plasma membrane away from the cell wall (see Pl. $1, b$ ). Normally growing $E$. coli is shown in Pl. 1, $a$. The plasmolysis was permanent when the plasma membrane was impermeable to the solute. The motility was unimpaired at moderate solute concentrations.

Spheroplasts. Stationary phase Escherichia coli after vacuum drying in $10 \%$ glucose followed by reconstitution with peptone water presented on examination a high proportion of spherical forms (Pl. 1, $c$ ) closely resembling protoplasts. Although many were still motile, none has so far been observed to divide or revert to its original shape and it seems unlikely that they are capable of producing colonies on nutrient agar. The proportion of spheroplasts formed could be greatly decreased by controlled rehydration similar to that already found to be effective on a macro scale. For example, a suspension of stationary phase $\boldsymbol{E}$. coli dried in $10 \%$ glucose was reconstituted in $\mathbf{5 0} \%$ glucose solution, a drop placed on the micro-culture chamber membrane and $\mathbf{5 0} \%$ glucose solution circulated beneath. The circulating glucose solution was slowly diluted by a drip feed of peptone water over a period of $4 \mathrm{hr}$. after which $68 \%$ of the bacteria in the fields examined were seen to be dividing.

It was possible to produce spheroplasts without recourse to the preliminary drying procedure by using bacteria harvested in the fragile logarithmic phase of growth. After standing for $\mathbf{1 ~ h r}$. in $\mathbf{5 0} \%$ sucrose on transfer to peptone water over $90 \%$ of the organisms assumed the spherical shape. Here again a gradual transfer to peptone water over a period of a few hours practically eliminated sphere formation and the majority of organisms resumed their normal role of growth and division.

The effect of sugar concentration on spheroplast formation. To produce the maximum number of spheroplasts it was found necessary to store the organisms in the sugar solution for a certain minimum time before transfer to peptone water. One hour was sufficient with sucrose over the concentration range examined (up to $2.5 \mathrm{M}$ ); glucose required a shorter time. Figure 4 shows the percentage of logarithmic phase organisms which formed spheroplasts after exposure for $1 \mathrm{hr}$. to glucose and sucrose at various concentrations. Spheroplast formation did not occur spontaneously on transfer to peptone water and counts were made $1 \mathrm{hr}$. after the transfer to allow completion of the process. Spheroplast formation commenced at a certain threshold sugar concentration and increased with rising concentration, rapidly in the case of sucrose, more gradually with glucose. With Escherichia coli in the stationary phase, spheroplasts were formed only after a longer period in the sugar solution, presumably owing to the enhanced thickness and strength of the cell wall in this phase.

Suppression of spheroplast formation by polyethylene glycol. High molecular weight substances which are unable to permeate the cell wall will exert their full osmotic pressure against it and compress it against the plasma membrane. Thus, the plasmolysis seen in $10 \%$ sucrose disappeared on the addition of $10 \%$ polyethylene glycol and the bacteria assumed a marked flattened appearance (Pl. 1, d). This could best be seen when the organisms were freely moving in the surrounding fluid so that they presented a continually changing orientation. A supersaturated solution of raffinose $(50 \%)$ produced flattening in an enhanced degree and this persisted for some hours, suggesting that the trisaccharide was permeating the cell wall only very slowly. A similar appearance resulted on suspending the organisms in $50 \%$ sucrose, but in this case the flattening was only transient, giving way after about 
15 min. to a pronounced plasmolysis, presumably after equilibrium had been reached across the cell wall. However, the flattened shape could be restored at this stage by the addition of $10 \%$ (i.e. $0.01 \mathrm{~m}$ ) polyethylene glycol and appeared to be permanent. These observations suggest that the cell wall lacked any appreciable rigidity since mild external forces caused its collapse on to the contracted protoplast.

The effect of the colloid concentration. A suspension of Escherichia coli (logarithmic phase) in $2.5 \mathrm{M}$-glucose containing various concentrations of polyethylene glycol was placed on the cellophan membrane of the micro-culture chamber. After $1 \mathrm{hr}$. the glucose was removed by circulating peptone water beneath the membrane. After a further hour the percentage of organisms converted to spheroplasts was assessed by counting several fields comprising about 1000 organisms. As seen in Fig. 5, spheroplast formation decreased progressively with increasing concentrations of polyethylene glycol, from $80 \%$ in the sugar alone down to $5 \%$ in the presence of $10 \%$ polyethylene glycol.

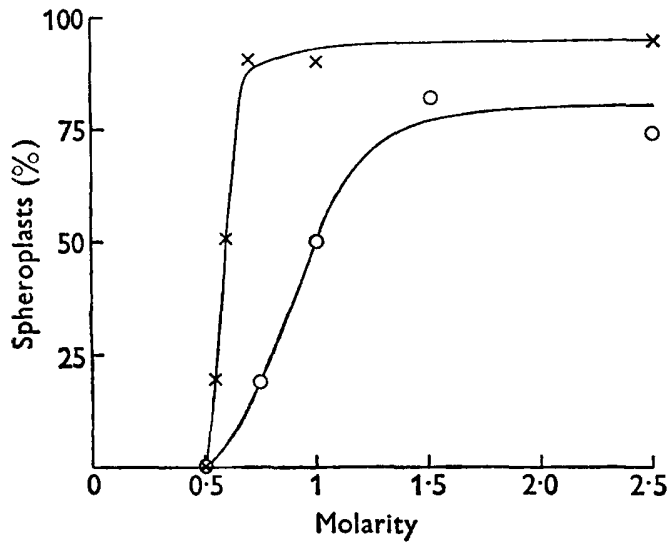

Fig. 4

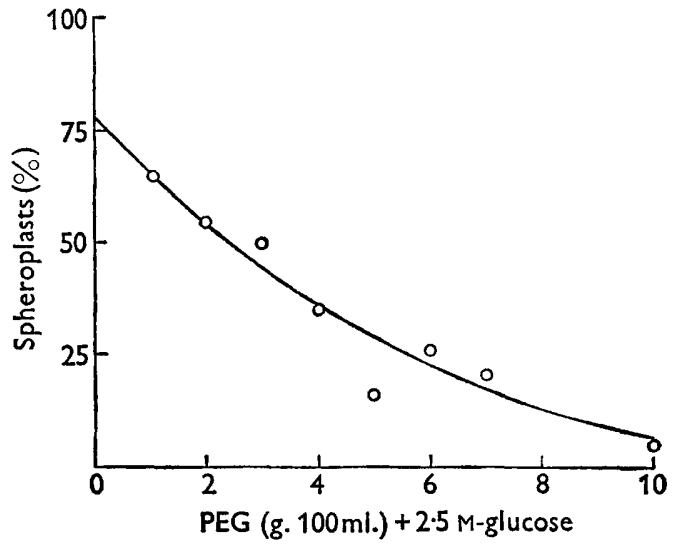

Fig. 5

Fig. 4. Spheroplast formation in Escherichia coli (logarithmic phase) due to glucose (O), and sucrose $(x)$.

Fig. 5. Suppression of spheroplast formation in Escherichia coli (logarithmic phase) by PEG.

\section{Pellet volume measurements}

Independent evidence of the contraction in the bacterial cell volume, caused in plasmolysed bacteria by high molecular weight substances, was obtained from measurements of pellet volume in the analytical ultracentrifuge.

The effect of centrifugal force on the pellet volume of Escherichia coli in various media. Figure 6 shows the pellet volumes expressed as ml./g. dry wt. organism over a wide range of centrifugal forces. The pellet volumes refer to the volume as measured after running for $1 \mathrm{hr}$. at each speed by which time an equilibrium value was closely approached. Measurements made on deceleration of the rotor after reaching full speed, again running for $1 \mathrm{hr}$. at each speed, gave pellet volumes in close agreement with those measured during acceleration in the case of suspensions in water and $0 \cdot 15 \mathrm{M}-\mathrm{NaCl}$, but showed a marked hysteresis in $0.5 \mathrm{M}-\mathrm{NaCl}$ especially in the presence of polyethylene glycol. The actual curve obtained was to some extent dependent on 
the pretreatment of the bacteria; for example, water-washed organisms transferred to $0 \cdot 15 \mathrm{M}-\mathrm{NaCl}$ showed substantially smaller pellet volumes than when washed directly in $0 \cdot 15 \mathrm{M}-\mathrm{NaCl}$; they also showed plasmolysis. Attempts were made to measure pellet volumes at zero centrifugal force after removing the ultracentrifuge cell from the rotor at the end of an experiment, but these showed a progressive increase with time. This was especially marked in the case of the polyethylene glycol runs when the pellet at the end of the run still had the same volume as when at full speed and showed a slow expansion over many hours, presumably depending on the rate of diffusion of polyethylene glycol away from the pellet. As seen from Fig. 6 the pellet volume decreased with increasing centrifugal force, no doubt due partly to the expulsion of interstitial fluid from between the bacteria as they suffered deformation under the applied force, and partly to loss of fluid from within. The rate of decrease in pellet volume with increasing centrifugal force was greatest at low centrifugal forces, as would be expected from osmotic considerations.

The force acting on the pellet. At a depth $d \mathrm{~cm}$. below the surface of the pellet, the compressive force $\boldsymbol{P}$ acting on the organisms, mean density $\rho_{1}$, in a medium of density $\rho$, will amount approximately (when $d$ is small) to

$$
\begin{aligned}
\boldsymbol{P} & =\frac{w^{2} r}{\boldsymbol{g}}\left(\rho_{1}-\rho\right) d g . / \mathrm{cm}^{2} \\
& =\frac{w^{2} r\left(\rho_{1}-\rho\right) d}{\boldsymbol{g} \times \mathbf{7 6} \times \mathbf{1 3 \cdot 6}} \text { atmospheres, }
\end{aligned}
$$

where $w=$ angular velocity of rotor (radians/sec.) and $r=$ distance of pellet layer from centre of rotation (see Sharp, Beard \& Beard, 1950). Thus for the case of washed organisms in a field of $100,000 \mathrm{~g}$, where according to the graph (Fig. 6) the volume of organisms per g. dry weight $=4.3 \mathrm{ml}$., and the mean organism density (assuming a value of 0.71 for the partial specific volume of the cell material), is then about $\mathbf{1 \cdot 0 7}$, the compression at the bottom of a $1 \mathrm{~mm}$. thick layer amounts to about $\mathbf{0 . 7 0}$ atmosphere. The force of compression decreases practically uniformly to zero at the surface of the pellet, the average force at the centre being 0.35 atmosphere.

The hydrodynamic volume of the organisms. As a result of the unknown amounts of interstitial and intracellular fluid associated with the organisms in the pellet and their dependence on the centrifugal force, pellet volume measurements are not adaptable to the determination of the true hydration of bacteria. We have been unable to substantiate the claim made by Bendet, Smith \& Lauffer (1960) that these difficulties are overcome by sedimenting the organisms through an immiscible solvent and measuring the upward shift of the solvent boundary. Our measurements with a bromobenzene + kerosine lower layer of density 1.05 showed the same variation in pellet volume with increasing centrifugal force as pellet volumes measured directly, although of course the reversible effect on deceleration was no longer seen. Thus, although the mean hydration value for Escherichia coli given by Bendet et al. is of the same order as that calculated from the graph (Fig. 6) at the speed of $12,590 \mathrm{rev} . / \mathrm{min}$. used by these authors, it cannot be regarded as having any real significance. Nevertheless, pellet volume measurements made under comparable conditions at the same speeds provide an indication of changes in the volume and compressibility of organisms resulting from changes in the suspending media and are therefore of importance in the present study. 
The effect of $\mathrm{NaCl}$ concentration. The pellet volume of Escherichia coli in $0 \cdot 15 \mathrm{M}$ $\mathrm{NaCl}$ showed a marked diminution, at comparable centrifugal forces, of the volume in water (Fig. 6), no doubt as a result of a decrease in tension in the bacterial cell wall. Plasmolysis induced by increasing the $\mathrm{NaCl}$ concentration to $0.5 \mathrm{M}$ resulted in still further decrease in volume of pellet.

The effect of glucose and sucrose. The effect of glucose and sucrose at similar molarities was compared from measurements of the limiting pellet volumes attained at a given speed. The results (Fig. 7) are expressed as a percentage of the volume of the original (stationary phase) suspension of water washed Escherichia coli run under

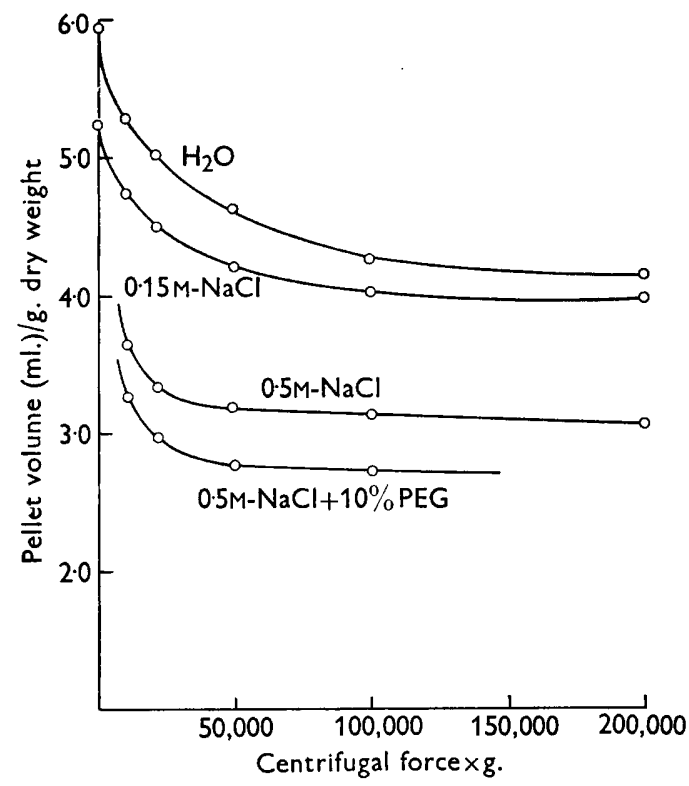

Fig. 6

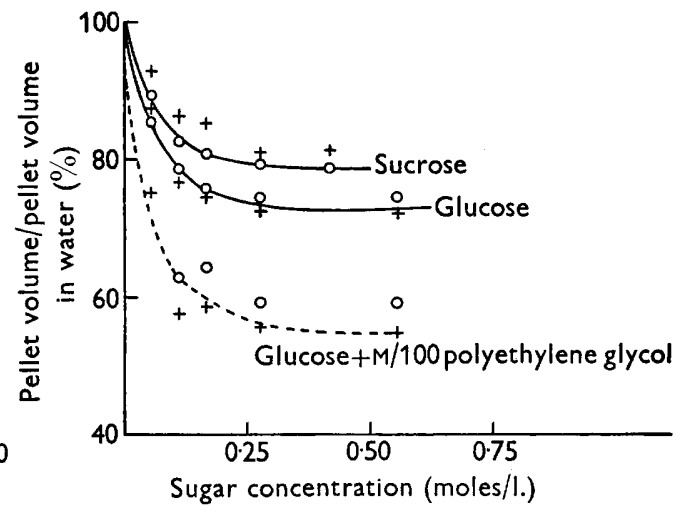

Fig. 7

Fig. 6. Variation in pellet volume of Escherichia coli (stationary phase) with centrifugal force.

Fig. 7. Contraction in pellet volume in glucose, sucrose and glucose $+M / 100$ PEG. $\bigcirc$, at $22,000 \mathrm{~g}$; + , at $100,000 \mathrm{~g}$.

identical conditions at each of two speeds $(12,590$ and $37,000 \mathrm{rev} . / \mathrm{min}$.$) , until no$ further contraction in the pellet volume occurred (1-2 hr.). On a molarity basis, the two sugars appeared to have a similar effect on the reduction in the pellet volume produced. (The slightly higher curve in the case of sucrose solutions may be the result of some reduction in compressive force due to their higher density.) Above $0.3 \mathrm{M}$, at which concentration plasmolysis was clearly evident, further increases in concentration had little effect in further reducing pellet volume.

The effect of polyethylene glycol. The addition to the bacterial suspension of a high molecular weight solute such as polyethylene glycol which does not penetrate the bacterial cell wall was found to cause a decrease in pellet volume at a given speed. The effect was most marked when the bacteria were already plasmolysed, e.g. in $0.5 \mathrm{M}-\mathrm{NaCl}$ (Fig. 6) or in the higher concentrations of glucose (Fig. 7). Although the 
concentration of the $10 \%$ polyethylene glycol solutions tested was low in terms of molarity ( $0.01 \mathrm{M})$, the osmotic pressure of such a solution approached 1 atmosphere (see next section), a value in excess of that imposed by the centrifugal force at the maximum safe rotor speed $(60,000 \mathrm{rev} . / \mathrm{min}$.$) .$

\section{Experiments with cellulose membranes}

To assess the magnitude of the external pressure exerted by high molecular weight materials against the bacterial cell wall, osmotic pressure $(\Pi)$ measurements were made in simple rise-tube osmometers with cellophan dialysis tubing (see methods). In addition, the temporary pressures produced by various low molecular weight substances, which freely permeated the cellophan membrane, were studied in relation to concentration $(c)$ and molecular weight.

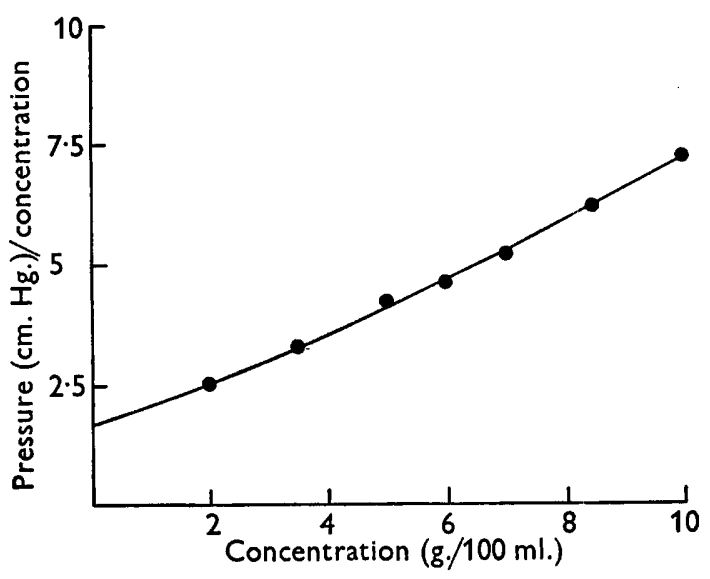

Fig. 8

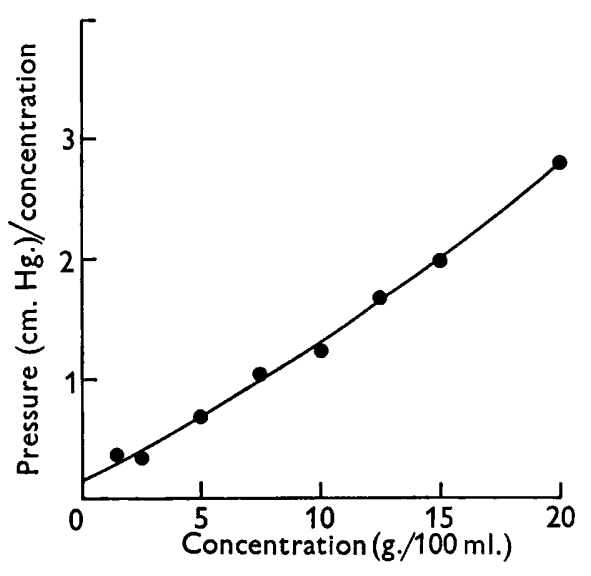

Fig. 9

Fig. 8. Osmotic pressure of PEG.

Fig. 9. Osmotic pressure of dextran.

High molecular weight substances. Osmotic pressure measurements made on polyethylene glycol (undialysed) at varous concentrations showed very little falling off with time in spite of the poly-dispersity of the material. The plots of $\Pi / c$ against $c$ (Fig. 8) showed a marked concentration dependence; the pressure of nearly 1 atmosphere for a $10 \%$ solution was over four times that calculated from the limiting value of $\Pi / c$ at zero concentration. Dextrans have proved effective and have been widely used as the colloid component in drying media. Figure 9 shows the $\Pi / c$ against $c$ relationship for a transfusion dextran of molecular weight 135,000 (Glaxo Laboratories Ltd.). Here also, considerable deviations from ideality occurred; the osmotic pressure of $12 \mathrm{~cm}$. $\mathrm{Hg}$ recorded for a $10 \%$ solution rose to $56 \mathrm{~cm}$. for a $20 \%$ solution.

Low molecular weight substances. When the solute is able to permeate the membrane, the pressures developed are transient and less than the true osmotic pressures. To obtain comparative results, the cellophan bags were tested with $0 \cdot 3 \mathrm{M}$-sucrose and selected to give peak pressures under the experimental conditions within $\pm 5 \%$ of $25 \mathrm{~cm}$. $\mathrm{Hg}$. The rate at which the pressure in the bag increased is shown for glucose at various concentrations in Fig. 10. A peak pressure was reached in 
each case in 1.5-2 hr. and thereafter fell away. Sucrose and raffinose attained peak pressures after a similar period of time. The peak pressures attained with $\mathrm{NaCl}$ and three different sugars (a mono-, di, and tri-saccharide) over a range of concentrations are shown in Fig. 11. The ratio of peak pressure to concentration increased in each case with rising concentration and at similar molarities the peak pressures increased with the molecular weight. Peak pressures of this order may possibly be sufficient to cause rupture of the bacterial cell wall, though in view of its relatively low permeability the pressures developed by glucose and sucrose within the cell are probably markedly greater. However, in the absence of any close structural analogy between cellophan and a bacterial cell wall, such deductions must be treated with some reserve.

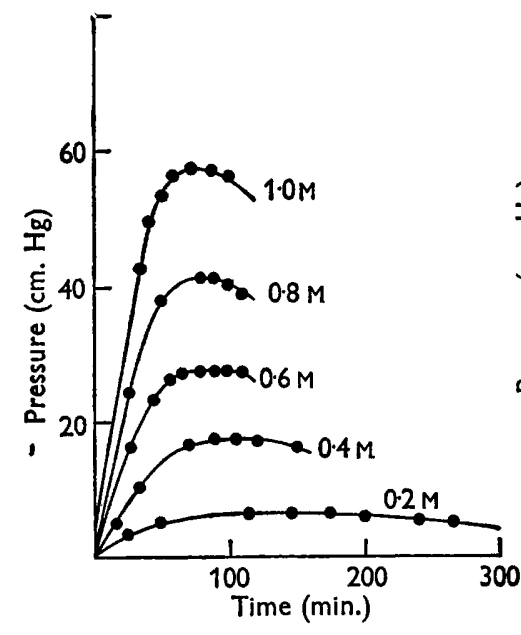

Fig. 10

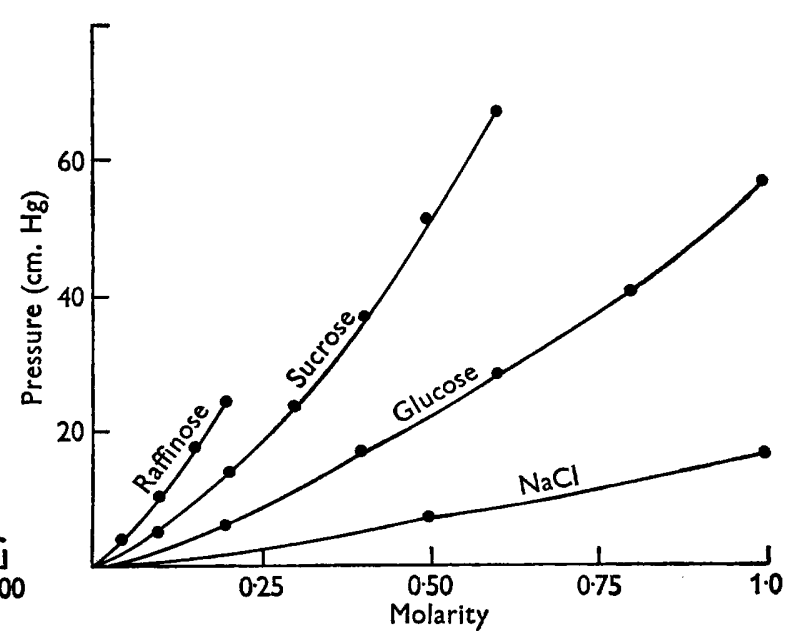

Fig. 11

Fig. 10. Diffusion pressures of glucose.

Fig. 11. Maximum pressures due to $\mathrm{NaCl}$ and sugars.

\section{DISCUSSION}

The concept of a bacterium as confined by a thin, rather impermeable plasma membrane supported by an outer, stronger and more permeable cell wall is now generally accepted. The phenomenon of plasmolysis, as displayed by various Gramnegative organisms in hypertonic solutions of electrolytes or sugars, such as glucose or sucrose, which readily permeate the cell wall but not the plasma membrane, is regarded as the result of the retraction of the plasma membrane away from the cell wall, due to osmotic forces. A hypothesis to explain the observations made in this paper is suggested on the basis of this concept. The plasmolysis induced by the sugar solution will result in an increased volume between the cell wall and plasma membrane and this space will, at equilibrium, be occupied by sugar solution of the same concentration as that outside the cell. On transfer to peptone water, the sugar solution, temporarily trapped between the bacterial cell wall and plasma membrane, will set up diffusion pressures which may be of sufficient magnitude to rupture the cell wall and release the spheroplast which, being no longer constrained by the 
tough cell wall envelope, assumes a spherical shape. The operation of such a mechanism will depend on the permeability properties to the sugar concerned, of both the cell wall and the plasma membrane. The cell wall, although permeable to the sugar, must present a sufficient barrier to its return passage to create temporary osmotic forces large enough to rupture the wall. On the other hand, unless the plasma membrane is impermeable to the sugar, the plasmolysis will be only temporary (e.g. as in the case of erythritol) and the cell as a whole may then suffer rupture on transfer to peptone water. The observation that the bacteria must remain for some time in the sugar solution in order to produce the maximum number of spheroplasts is in accord with the hypothesis, this time being that required for the sugar solution to reach equilibrium across the cell wall. The further observation that a period of time, up to $1 \mathrm{hr}$., was necessary after transfer to peptone water to produce the maximum number of spheroplasts suggests, however, that completion of the process may be dependent on some enzymic breakdown. How far, if at all, the spherical forms thus produced differ from the protoplasts prepared by the enzymic digestion of certain bacterial cell walls (see e.g. Weibull, 1953) is not at present known, but the technique may be of general interest in providing a new method of forming spherical bodies from Gram-negative bacteria without the agency of a foreign enzyme.

Although the survival of Escherichia coli when dried in a glucose solution and reconstituted in the ordinary way is poor, the large improvement in survival resulting from carefully controlled rehydration suggests that glucose alone has excellent preservative properties and that the low molecular weight component of effective preservation media is the primary protective agent. One of the consequences of the flattening in the shape of plasmolysed bacteria observed after the addition of a colloidal solution is a decrease in the amount of sugar held between cell wall and plasma membrane, thus mitigating the tendency to cell wall rupture on transfer to peptone water or, in the case of dried organisms, on reconstitution. It appears to be in this manner that the protective colloid plays its complementary role. The relatively small osmotic forces due to high molecular weight material acting against the cell wall appear to be sufficient to cause it to collapse upon the plasmolysed interior, although as a consequence of the marked deviations from ideality revealed by direct measurements of osmotic pressure, substantial pressures can result with such substances in the high concentrations which would occur during drying. No evidence was found to suggest a threshold concentration where the cell wall, if a rigid structure, might be expected to collapse suddenly under a certain critical pressure.

Most of our observations and experiments were made in liquid suspending media. It is necessary to be cautious in applying these results to the complex process which occurs during drying, especially when approaching dryness. It is clear, however, that if the low molecular weight component permeates the plasma membrane the high molecular weight material cannot fulfil its function of controlling the amount within the cell. On the other hand, effective agents such as glucose and sucrose which induce a more or less permanent plasmolysis of the cells and do not pass the plasma membrane barrier, presumably cannot afford any protection to the components of the cytoplasm and the nucleus which might have been expected to be most susceptible to damage on drying. The need for protection on drying therefore appears to lie mainly in protection of the cell wall and/or the outer surface 
of the protoplast where a number of enzymes are believed to be located. Thus, although the precise role played by the low molecular weight component in protecting the bacteria on drying is still largely a matter of conjecture, it appears that one of its most important functions is to preserve the cell wall intact. This it may do by replacing, rather than retaining, some of the water in the pores of the cell wall and so preventing its total collapse on drying.

The most effective preservative substances are generally very water-soluble and difficult to freeze-dry in the true sense, because of their tendency to supersaturate and to contract on drying to a glass-like residue which loses moisture extremely slowly in the final stages of drying. If drying proceeds in fact from the liquid phase, most of the cellular water will be removed by osmotic exchange rather than by direct evaporation or sublimation, and it is possible that less damage is thereby caused to the membrane structure.

In view of the marked flattening of bacteria observed after transfer to a $50 \%$ sucrose solution, giving way after $15 \mathrm{~min}$. to the characteristic plasmolysed appearance, it is conceivable that with the rise in concentration during drying from a liquid or semi-solid phase, certain substances having the appropriate physical properties could exert a self-limiting control on the amount entering the cell and thus give a satisfactory survival even in the absence of any high molecular weight component. The maintenance of survival on storage would then be very dependent on the completeness with which drying had been carried out since trace amounts of water, especially with a rise in storage temperature, would facilitate diffusion of more material into the cell, leading to an increased risk of cell wall rupture on reconstitution. The presence of a protective colloid would prevent such an occurrence in the manner already described, although the possibility that it may promote survival by the alternative process of modifying the physical properties, viscosity, etc., of the low molecular weight component cannot be dismissed.

These conclusions have been arrived at by study of Escherichia coli Jepp, but other Gram-negative bacteria namely Chromobacterium violaceum, Serratia marcescens and another strain of $\boldsymbol{E}$. coli (Porton, 164) all showed a similar behaviour in exhibiting a well-defined plasmolysis (presumably as a result of the ease with which the plasma membrane contracts away from the cell wall in hypertonic media) and all formed spheroplasts after transfer from concentrated glucose to peptone water. On the other hand, the Gram positive bacteria, Bacillus cereus in the vegetative form and Corynebacterium diphtheriae (gravis) and C. xerosis did not show plasmolysis, spheroplast formation or rupture after similar treatment. This accords with the tougher character of the Gram-positive group.

We wish to record our debt to Dr D. W. Henderson, F.R.S. for his special interest and encouragement in this work.

Our thanks are due to $\mathbf{M r}$ K. H. Grinstead for valuable assistance in carrying out the ultracentrifuge measurements. 


\section{REFERENCES}

ANNEAR, D. I. (1956). The preservation of bacteria by drying in peptone plugs. J. Hyg., Camb. 54, 487.

ANNEAR, D. I. (1958). Observations on drying bacteria from the frozen and liquid state. Aust. J. exp. Biol. med. Sci. 36, 211.

Bendet, I. J., Smith, C. E. \& LAUfFer, M. A. (1960). Hydrodynamic volumes determined by immiscible liquid displacement. Arch. Biochem. Biophys. 88, 280.

Fry, R. M. (1954). The preservation of Bacteria in 'Biological Applications of Freezing and Drying', ed. R. J. C. Harris. New York: Academic Press.

Fry, R. M. \& Greaves, R. I. N. (1951). The survival of bacteria during and after drying. J. Hyg., Camb. 49, 220.

HegarTy, C. P. \& WeEks, O. B. (1940). Sensitivity of $E$. coli to cold shock during the logarithmic growth phase. J. Bact. 39, 475.

HeLler, G. (1941). A quantitative study of environmental factors involved in survival and death of bacteria in the desiccated state. J. Bact. 41, 109.

Miles, A. A. \& Misra, S. S. (1938). Estimation of the bactericidal power of blood. J. Hyg., Camb. 38, 732.

Powel., E. O. (1956). An improved culture chamber for the study of living bacteria. J. R. micr. Soc. 75, 235.

ReCORD, B. R. \& TAYLOR, R. (1953). Some factors influencing the survival of Bact. coli on freeze-drying. J. gen. Microbiol. 9, 475.

Scotr, W. J. (1959). Death during storage of dried micro-organisms, in Recent research in freezing and drying, ed. by A. S. Parkes \& A. U. Smith. Oxford: Blackwell.

Sharp, D. G., Beard, D. \& Beard, J. W. (1950). Partial specific volume and water content of influenza virus. J. biol. Chem. $182,279$.

SNYDER, T. L. (1947). The relative errors of bacterial plate-counting methods. J. Bact. 54,641 .

WeIBull, C. (1953). The isolation of protoplasts from Bacillus megaterium by controlled treatment with lysozyme. J. Bact. 66, 688.

\section{EXPLANATION OF PLATE}

Plate I

Escherichia coli (logarithmic phase) viewed by phase contrast illumination: (a) Growing freely in peptone water. (b) Plasmolysed in M-glucose. (c) Spheroplasts formed after transfer from 1.5 Msucrose to peptone water. $(d)$ Flattened bacteria in $\mathrm{M}$ glucose with $10 \%$ polyethylene glycol. 

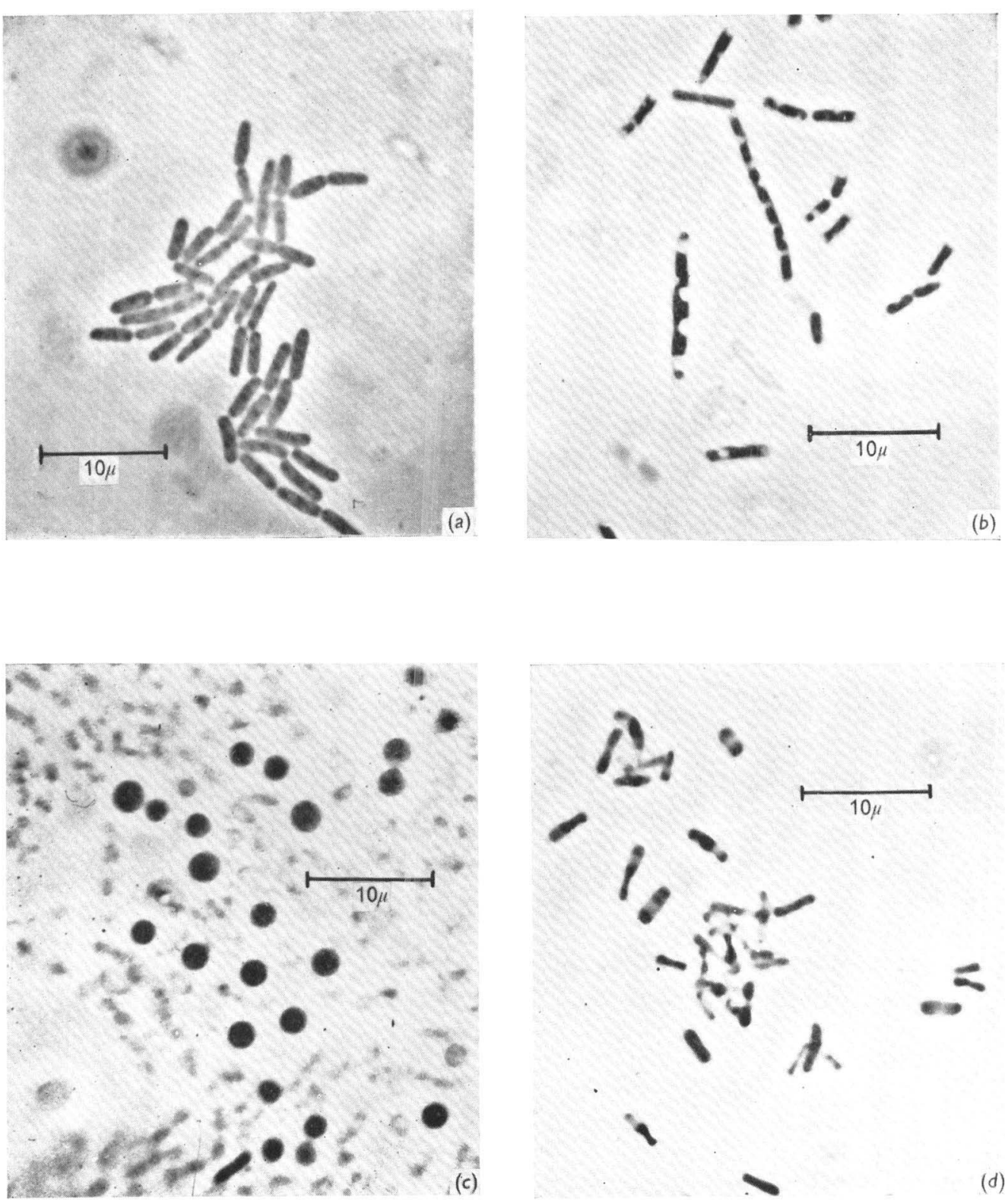

B. R. RECORD, R. TAYLOR AND D. S. MILLER

(Facing $p$. 598) 
